\title{
Business Process Reengineering-A Case Study on Computer Center Service
}

\author{
Soontorn Phiphopsuthipaiboon and Somjai Boonsiri \\ Department of Mathematics and Computer Science, Faculty of Science, Chulalongkorn University, Bangkok, Thailand
}

\begin{abstract}
This paper used Business process reengineering (BPR) for improve operation of computer service processes in the computer center. Change of service processes were conducted by implementing four-phase: 1) Finding of current process 2) Analysis current process 3) Redesign Process 4) Applying new process and realization framework to support redesign decision making. The framework based on policies and rules of organization. Finally, the new process was implemented at the computer center. The results showed that the new process was better than the current process, time of service decrease and reduce workload.
\end{abstract}

\section{Introduction}

Business Process Reengineering (BPR) is a powerful approach to bring in extraordinary improvements in the output of an organization [1]. This approach focus on business process optimization by improvement performance such as speed, cost, shareholder value, customer orientation, quality and service [2][3][4]. BPR were used in every organization for increase satisfaction of customer to get advantages over competition company. By measure quality of service, it has many type of quality and this paper focus on cycle time and performance of service. BPR cycle can be illustrated in the following way (Fig. 1).



Figure 1. Business process reengineering cycle.

Process is a collection of activities across time and space from start until finish that identifies one or more kinds of input and creates an output that is of value to the customer [5], [6].

In recent years, growth in computer center service has increased not only the number of center but also the size, breadth and complexity of their operations because customer can access to complexity application online or system more than previous time. The computer center service may service many organization or may be devoted to one organization. Computer center service can become a part of every organization such as bank, hospital, restaurant or academy [7].

This paper found problems about request documentation and waiting time for computer service. Data analysis found the process of request documentation had many unnecessary steps and took a long time for assignment task process. When the problems could not solve in time. It had transformed into complicate problems like virus computer that damages on computer and infected to other computers. It affects the performance of the organization. With these reasons it necessary to created new process to solve all problems.

\section{Problems statement}

The problems found on this paper, show as following;

1) Request documentation process took a long time.

2) Current process has many steps.

3) Increased workload because problem is more complicate due to prolonged waiting time of service.

\section{Framework}

This paper created framework (Fig. 2) for support redesign decision making [8], as following;

1) Duration time on each step recommended by leader of computer service center, who responsible for effective and efficient functioning of that particular process. He should understand the step in entire process and be able to predict how any proposed changes might affect both the process and organization. By Data analysis from the current process found each period waste time at least 1 hours. So the step took a time over 1 hours called suspected unnecessary step. 
2) Identify suspected unnecessary step which considering fact and impact in computer service process.

3) Verify unnecessary step with policy and rules of organization. The step covered by policy or rules of organization then changed status to necessary step.

4) Verify all necessary steps by 3 executives of computer center. When the step could be changed then called unnecessary step.



Figure 2. Framework for support redesign decision making.

\section{Method}

\subsection{Finding current process.}

Identification of current process and basic information which necessary for create the new process. This paper the researcher had interviewed leader, reviewed old worksheet and observed the behaviour of customers and officers in current process.



Figure 3. The current business process model.
From Fig. 3, it was divided in 4 phase. The first was documentation stage to request service. The second was assignment stage for distribute work to officer. The third was work stage to resolve problem and the fourth stage was verification stage for verify the job was done correctly. The current process had 8 related persons and each person had role in process as follows:

- Customer - the person who sent request documentation and verified the process performance.

- General Service officer (customer) - the person who sent request documentation to leader.

- Leader (customer) - the person who approved request documentation.

- Messenger - the person who sent request documentation to general service officer (computer center division).

- General Service officer (computer center division) the person who received request document and coordinator between customer, leader, section leader and officer.

- Leader (computer center division) - the person who is assign task to section leader and verify when the task success.

- Section leader (computer center division) - the person who distributed task to officer and guarantee the task of officer were properly.

- Officer - IT support.

\subsection{Current process analysis.}

The fishbone (Ishikawa) diagram identifies many possible causes and problem [9] about delay service.



Figure 4. Fishbone diagram.

From Fig. 4 the fishbone diagram define any possible cause specific problems of computer service, which took a long time as following; 
Method are divided into 2 cause that are the method has a lot of step and waiting time in request documentation.

Equipment could not reserve such as hard disk, power supply, mouse, keyboard etc. And procurement process has many steps.

Environment, this problem were restrictions on the area such as distance, security and limit access for each department

Man, officer had difference skill and they could not job rotation.

The information analysis can be summarized as follows: 1) Unnecessary processes were several steps 2) Certain regulatory inducing waiting time. Solution: 1) Unnecessary processes elimination 2) Modify processes for reduced waiting time 3) Modify the regulatory restrictions on current processes.



Figure 5. New business process model

\subsection{Redesign process}

This paper uses a framework for decision making process at each step in the current process. The results have led to creation of the new process. (Fig. 5)

From Table 1 showed status of the step on the framework analysis, each step used framework for decision making, as showed in Fig. 2. The result showed 10 unnecessary steps; 9 steps could be change but only step could not change because this step cover by policy. A necessary could be change for reduce waiting time. Finalize the new process was create with many method like eliminate, create, separate, combination and parallel process, as show in Fig. 5

The new process could reduce related person from 8 to 5 peoples and reduce the step in process from 17 to 11 steps. The new business can describe by person role as following;

- Customer - the person who were call by internal phone to request service.

- General Service officer (computer center division) the person who were call center, wrote request documentation and sent documentation to officer.
- Leader (computer center division) - the person who verified the final step.

- Section leader (computer center division) - the person who mention officer for complexity job.

- Officer - IT support.

Table 1. The framework of current process

\begin{tabular}{|c|c|c|c|c|c|c|c|}
\hline №. & Proceses tase & $\begin{array}{c}\text { Tme using } \\
\text { over } 1 \mathrm{Hr} \text {. } \\
\text { (YN) }\end{array}$ & $\begin{array}{c}\text { Necsssy } \\
\text { (YN) }\end{array}$ & $\begin{array}{l}\text { Ruse esver } \\
\text { (YM) }\end{array}$ & $\begin{array}{c}\text { Imporo/4 } \\
(\mathrm{MN})\end{array}$ & Result & Processs ouret \\
\hline 1 & Wifle problem detsil on papes. & No & . & . & No & Net ehanget & customer \\
\hline 2 & Oeresate deportrentil division number. & $Y_{6 s}$ & No & No & . & Chenge & $\begin{array}{l}\text { Gereres Sentice offices } \\
\text { (Customar) }\end{array}$ \\
\hline 3 & Signature. & Yes & No & No & , & Chenge: & Lesder(Customer) \\
\hline 4 & Sont paper to divison. & Yes & No & No & . & Crenge & Messanger(faculy) \\
\hline 8 & Geneste clisision rescilat rumber. & Yes & No & No & . & Chenge & $\begin{array}{l}\text { Genaral Sentico onticer } \\
\text { [Divison] }\end{array}$ \\
\hline 8 & Signalue & Yes & No & No & . & Orngt & Iteder(Division) \\
\hline 7 & Sent paper to Section Leaver. & $\gamma_{65}$ & No & No & . & Crangs &  \\
\hline 8 & Distribute work to offiser. & Yes & No & No & 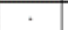 & Chengo & Soction Lesdor[Didision] \\
\hline 9 & Contact boustemet. & No & . & $\cdot$ & Yes & Chengt & offect \\
\hline 10 & Sohedule time: & $N_{0}$ & . & - & No & Net chsnge & customer \\
\hline 11 & Sovise customer. & Yes & Yes & . & Yes & Cronge & officer \\
\hline 12 & Signature. & $N_{0}$ & . & . & No & Not onarge & Customor \\
\hline 13 & Sent paper to Sestion Leadcri. & Yes & No & No & . & Chenge & offerer \\
\hline 14 & Signgive & Yes & No & No & . & Conget & Section Leader:[Disusion] \\
\hline 15 & Sent poper io Lesder. & $\gamma_{65}$ & $Y_{66}$ & . & No & Nat ehange: & $\begin{array}{l}\text { Gererers Senice offices } \\
\text { (Dwision) }\end{array}$ \\
\hline 16 & Signaure. & Yes & $Y_{e s}$ & . & No & Nat onarge & Ladsor(divition) \\
\hline 17 & Store fapes: & Yes & No & Yas & No & Nat oherge & $\begin{array}{l}\text { Gerenal Sentico oftices } \\
\text { [Divison] }\end{array}$ \\
\hline
\end{tabular}

\subsection{Applying new process}

The new process was implemented. This paper focus on the service processes and uncontrolled individual factors.

\section{Result}

The quantity of computer service between the current process and the new process showed 172 working times and 166 working times respectively. The numbers of service in both scenarios were similar, as showed in Table 2

Table 2. Quantity of computer service.

\begin{tabular}{|c|c|c|}
\hline Type of service & $\begin{array}{c}\text { Current Process } \\
\text { (working times) }\end{array}$ & $\begin{array}{c}\text { New Process } \\
\text { (working times) }\end{array}$ \\
\hline Software service. & 119 & 93 \\
\hline Network service. & 31 & 42 \\
\hline Hardware service. & 22 & 31 \\
\hline Total & 172 & 166 \\
\hline
\end{tabular}

Table 3. The waiting time for request documentation (minute/working times) between the current process and the new process

\begin{tabular}{|c|c|c|}
\hline Type of service & $\begin{array}{c}\text { Current process } \\
\text { (minutes) }\end{array}$ & $\begin{array}{c}\text { New process } \\
\text { (minutes) }\end{array}$ \\
\hline Software service. & 1234 & 30 \\
\hline Network service. & 1254 & 30 \\
\hline Hardware service. & 1003 & 30 \\
\hline Average & 1163 & 30 \\
\hline
\end{tabular}

From data analysis found the process of request documentation had many unnecessary steps and took a 
long time for assignment task process. After implementation, it reduced waiting time for request documentation $1133 \mathrm{~min} /$ working times, as showed in Table 3

Table 4. The Cycle time for service processes (day/working times) between the current process and the new process

\begin{tabular}{|c|c|c|}
\hline Service types & $\begin{array}{c}\text { Current process } \\
\text { (days) }\end{array}$ & $\begin{array}{c}\text { New process } \\
\text { (days) }\end{array}$ \\
\hline Software service. & 2.92 & 1.51 \\
\hline Network service. & 2.68 & 1.17 \\
\hline Hardware service. & 2.10 & 1.41 \\
\hline Total & 2.57 & 1.36 \\
\hline
\end{tabular}

From Table 4 presented cycle time for service processes was 2.57 day/sample for current process and $1.36 \mathrm{day} / \mathrm{sample}$ for new process. The new process reduced cycle time for service processes 1.21 day/working times

Table 5 presented an impact of time lags was that the effect of the operation did not work as planned, which had rework. The number of rework was 18 times (10.47\%) in current process and 2 times in new process $(1.20 \%)$.

Table 5. Quantity of rework between the current process and the new process

\begin{tabular}{|c|c|c|}
\hline Service types & $\begin{array}{c}\text { Current process } \\
\text { (sample) }\end{array}$ & $\begin{array}{c}\text { New process } \\
\text { (sample) }\end{array}$ \\
\hline Software service. & 14 & 2 \\
\hline Network service. & 4 & 0 \\
\hline Hardware service. & 0 & 0 \\
\hline Total & 18 & 2 \\
\hline
\end{tabular}

\section{Conclusion}

This paper used BPR cycle to improve the process and presented framework for support redesign decision making, which created new process that suitable to environment of organization.

The new process of computer service center is better than the current process by resulting in 3 items of the performance improvement. Because the new process reduced 6 unnecessary steps especially in request documentation that took a long time (Table2). The request documentation was changed to call center system that reduced time 1133 minutes/sample (Table 3) compliance with Hammer and Champy study. Stewart [10] claimed that Bell Atlantic reduced the time of new telecommunication circuits installation from 16 days to just hours. Finally, we could optimized the task assignment due to reducing the rework.

Summary, after applying BPR. It was successful to decreased cycle time and waiting time as Sung J. Shim study [11] and Doomun study [12]. When implement on organization the result going on the same way according to Chou, Ghannouchi and Zhang study [13] [14] [15].

\section{References}

1. S. Mohapatra, Business Process Reengineering Automation Decision Points in Process Reengineering Springer, (2013).

2. U. G. Seebacher, Cyber Commerce Reframing: The End of Business Process Reengineering? Springer, (2002).

3. D. J. Elzinga, T. R. Gulledge and Chung-Yee Lee., Business process engineering: advancing the state of the art Springer, (1999).

4. M. Hammer and J. Champy, Reengineering the Corporation: A Manifesto for Business Revolution(Nicholas Brealey Publishing), (2001).

5. M. Hammer and J. Champy, Reengineering the Corporation: A Manifesto for Business Revolution (Harperbusiness), (1993).

6. T.H. Davenport, Process Innovation: Reengineering Work Through Information Technology (Harvard Business School Press), (1993).

7. R.S. Roussey, THIRD-PARTY REVIEW OF THE COMPUTER SERVICE CENTER., Journal of Accountancy, 146, (1978).

8. M. Abdous, Towards a Framework for Business Process Reengineering in Higher Education, Journal of Higher Education Policy and Management, 33 (2011).

9. D. E Lighter, D. C. Fair, Principles and Methods of Quality Management in Health Care, Aspen Publishers, (2000).

10. T.A. Stewart, Re-Reengineering. The Hot New Management Tool (Fortune), (1993).

11. R.M. Doomun and N.V. Jungum, Business process modelling, simulation and reengineering:call centres, Business Process Management Journal, 14, (2008).

12. S. J. Shim and A. Kumar, Simulation for emergency care process reengineering in hospitals, Business Process Management Journal, 16, (2010).

13. Y.C. Chou, B.Y. Chen and others, Prescription-filling process reengineering of an outpatient pharmacy, Journal of Medical Systems, 36, (2012).

14. S.A. Ghannouchi, K. Mabrouk and S. Ghannouchi, Proposal of data warehouse in the context of healthcare process reengineering, Business Process Management Journal, 16, (2010).

15. Zhang, R. J. Jiao, Q. Ma, Accountability-based order fulfillment process reengineering towards supply chain management, Journal of Manufacturing Technology Management, 21, (2010). 